\title{
Corporate Financial Policy and Taxation in a Growing Economy
}

\section{Citation}

Feldstein, Martin, Jerry Green, and Eytan Sheshinski. 1979. Corporate financial policy and taxation in a growing economy. Quarterly Journal of Economics 93(3): 411-432.

\section{Published Version}

http://dx.doi.org/10.2307/1883166

\section{Permanent link}

http://nrs.harvard.edu/urn-3:HUL.InstRepos:3203643

\section{Terms of Use}

This article was downloaded from Harvard University's DASH repository, and is made available under the terms and conditions applicable to Other Posted Material, as set forth at http:// nrs.harvard.edu/urn-3:HUL.InstRepos:dash.current.terms-of-use\#LAA

\section{Share Your Story}

The Harvard community has made this article openly available.

Please share how this access benefits you. Submit a story.

\section{Accessibility}




\title{
CORPORATE FINANCIAL POLICY AND TAXATION IN
}

\section{A GROWING ECONOMY*}

\author{
MARTIN FELDSTEIN \\ JERRY GREEN \\ EYTAN SHESHINSKI
}

I. A model of financial equilibrium, 412.-II. Effects of changes in the profit tax rate, 418.-III. Effects of changes in the taxation of retained earnings, 423.-IV. The nonneutrality of the corporate income tax, 427.- V. Conclusion, 430.

This paper presents a model of corporate financial policy in a growing economy and then uses this model to study the effects of changes in corporate and personal taxes. Our picture of the firm includes a flexible debt-equity ratio and a flexible dividend payout rate. The costs to the firm of both debt and equity capital are increasing functions of the firm's debt-equity ratio. We use a realistic description of the tax system that includes a corporate income tax with deductible interest expenses, a personal income tax, and a favorable tax treatment of retained earnings.

Our work builds on earlier research ${ }^{1}$ on both corporate finance and taxation but provides a more general and realistic model. This new model implies a unique optimal debt-equity ratio instead of the indeterminacy associated with the Modigliani-Miller tradition. The model also implies that firms will choose a positive equilibrium payout rate in spite of the favorable taxation of retained earnings. We know of no other model that explains why firms simultaneously borrow and pay dividends in an economy with corporate and personal taxation.

The model is presented and explained in Section I. The second and third sections then examine the effects of changes in the corporate tax rate and in the differential between the taxation of dividends and of retained earnings. The nonneutrality of the corporation tax is discussed more generally in Section IV.

* We are grateful to the National Science Foundation for financial support under grant numbers SOC75-14656, SOC71-03803, and SOC74-11446. This paper is part of the NBER Research Program in Business Taxation and Finance. The revision of this paper benefited from comments by participants in the NBER workshop, by a referee of this Journal, and by Alan Auerbach, Gregory Ballentine, Joel Slemrod, and Lawrence Summers.

1. See in particular Harberger [1962], Modigliani and Miller [1958], Miller [1976] and its useful bibliography, Lintner [1964], Solow [1971], Stiglitz [1973, 1976], and Jakobsson [1974], as well as our own previous research reported in Feldstein, Green, and Sheshinski [1978]. 
The framework for our analysis is an economy in steady-state growth with a fixed saving rate. To avoid the usual complexities and ambiguities of corporate tax shifting in a two-sector model, we assume that all business activity takes a corporate form. These simplifying assumptions allow us to focus on the effects of the tax system on financial behavior (the debt-equity ratio and the dividend payout rate) and on the after-tax yields on stocks and bonds. The implications of recognizing a noncorporate business sector and of allowing the saving rate to vary with asset yields are discussed briefly in Section IV.

\section{A Model of FinanCIAL EqUILIBRIUM}

In order to study these questions, we extend the simple onesector, nonmonetary growth model to include a specification of the financial behavior of firms and households. By virtue of the assumptions that aggregate savings are insensitive to the rate of return and that population grows exogenously at a fixed rate $n$, the economy's capital-labor ratio will be constant in the long-run equilibria that we analyze. Under the usual neoclassical conditions, this means that the gross rate of return per unit of capital $f^{\prime}$ is also a constant.

In the following subsections we discuss the behavior of firms and investors in the context of a simple tax structure that is designed to capture the basic features of the U.S. tax system.

\subsection{Firms' Decisions and the Post-and Pre-Tax Returns}

The decision variables on which we focus are concerned with the way in which investment is financed. There are two financial instruments, debt and equity; the proportion of capital financed by debt is denoted $b$. Firms must also choose their payout rate $p$, which is the fraction of the total return to equity holders (before any personal taxes are paid) that they receive in the form of dividends.

As a first step in the analysis, it is necessary to relate the netof-tax yields of investors to the corresponding costs of finance to firms. Debt costs the firm $i$ per unit of capital raised, and this return is taxed at the personal interest income rate $\theta$. Thus, the net rate return to bond holders is

$$
i_{N}=i(1-\theta) .
$$

The return to equity is $e$ and consists of $p e$ paid in the form of dividends and $(1-p) e$ retained for capital accumulation by the firm. ${ }^{2}$

2. This assumes that the increase in the market value of the firm resulting from acquiring a dollar's worth of capital goods is one dollar; i.e., that Tobin's parameter $q$ equals one [Tobin, 1969]. This is a crucial difference between our analysis and that of Auerbach [1979] and Bradford [1978]. 
We assume that dividends are taxed at the same rate as interest but that retained earnings are in effect taxed at a lower rate $(\mu \theta)$, where $\mu$ is between zero and one. The reason for the effectively preferential treatment of retained earnings is that no personal taxes are levied on corporate income held within the firm. Taxes are paid upon realization of the resulting gains, but they are below the ordinary income tax rate both because of the differential treatment of capital gains and because of the delay.that is typically entailed in taxing only realized capital gains. Overall, the net return to equity is, therefore,

$$
e_{N}=p e(1-\theta)+(1-p) e(1-\mu \theta) \text {. }
$$

It will be convenient to have a special symbol for the effective rate of taxation on equity income, which depends on the firm's control variable $p$ as well as the tax rate; let

$$
x=p(1-\theta)+(1-p)(1-\mu \theta)
$$

so that

$$
e_{N}=e x \text {. }
$$

Before the decisions of the firm can be studied, we must describe the economic environment in which it is embedded. Its securities must compete with those of other firms that are substitutes, but not perfect substitutes because their risk characteristics differ. From the household investors' point of view, the relevant variables are assumed to be the expected returns net of tax offered on the two types of securities issued, and the risk characteristics of these assets as determined by the debt-equity ratio the firm has chosen.

We shall use carets to denote the variables relating to all other firms collectively considered; the offered returns are $\hat{e}_{N}$ and $\hat{i}_{N}$ for equity and debt, respectively. The debt per unit of capital held by all other firms is $\hat{b}$.

In an equilibrium the firms' sources and uses of funds must be in balance. Its gross income per unit of capital is $f^{\prime}$. Interest costs of $b i$ per unit of capital are deductible for tax purposes. The residual is taxed at the rate $\tau$. The return to equity holders per unit of equity before personal taxation is thus defined as

$$
(1-\tau)\left(f^{\prime}-b i\right) /(1-b)=e .
$$

We assume that a firm, in marketing its. securities, perceives rising supply prices for both debt and equity capital as its debt-equity ratio rises. ${ }^{3}$ This assumption is clearly contradictory to the extreme

3. We assume that both prices rise, although our analysis requires only that at least one rise. 
form of the Modigliani-Miller view that the debt-equity ratio has no effect on the costs of either debt or equity. As we note below, this Modigliani-Miller view is not compatible with an interior solution for corporate debt policy. We also share the view of Myers [1977] and others that a high debt-equity ratio restricts a firm's real investment options, thereby reducing the value of its shares. In addition, we reject the extreme view that "home-made leverage" and corporate leverage are perfect substitutes.

It will be most convenient to express these schedules as giving the net required return to investors. They also depend upon the debt-equity ratio of all other firms $\hat{b}$, and their promised returns to the two types of securities, net of personal taxes $\hat{i}_{N}$ and $\hat{e}_{N}$ :

$$
\begin{aligned}
i_{N} & =\phi\left(b, \hat{b}, \hat{e}_{N}, \hat{i}_{N}\right) \\
e_{N} & =\psi\left(b, \hat{b}, \hat{e}_{N}, \hat{i}_{N}\right) .
\end{aligned}
$$

Higher returns available elsewhere, $\hat{e}_{N}$ and $\hat{i}_{N}$, shift these schedules up. More riskiness in the "market" portfolio $\hat{b}$ will have the opposite effect. We shall assume that the cross-partials of the $\phi$ and $\psi$ schedules are zero. ${ }^{4}$

We are now ready to discuss the way in which firms operate. Firms choose $b$ and $p$ so as to minimize the net cost of capital $N$, defined as

$$
N=b(1-\tau) i+(1-b) e .
$$

It is important to remember that $i$ and $e$ in this formula are interpreted as the supply prices to the firm. The economic actions of other firms enter into this decision problem as parameters of the $\phi$ and $\psi$ functions. Note that minimizing the cost of capital is equivalent to maximizing the present value of the equity in the company with our assumption that a dollar of retained earnings adds one dollar to the market value of the firm. ${ }^{5}$

Although it is clear that the risk considerations that make the firm's costs of debt and equity an increasing function of $b$ cause the firm to find an optimal mixture of debt and equity, it is natural to ask why such a firm would ever pay dividends. By retaining everything possible $(p=0)$, the firm can apparently lower the effective tax rate on equity earnings $(x)$ and thus lower the cost of equity finance as-

4. Perhaps a more natural assumption would be that the elasticities with respect to $b$ are independent of the levels of the other variables, but this would complicate the comparative statics significantly, without adding much of interest. The results do not depend in any way on the assumed effects of $\hat{e}_{N}, i_{N}$, and $\hat{b}$ on the individual firm's cost of funds schedules. [1979].

5 . This equivalence is discussed by Auerbach in the current issue of this Journal 
sociated with any fixed level of the net return to equity holders. Since $p$ is not an argument of $\phi$ or $\psi$, the policy $p=0$ would seem always to be the best.

The answer to this line of argument is that if all earnings were retained, the equity of the firm would grow at a rate equal to the rate of return on equity gross of personal income tax. In order to maintain ${ }^{6}$ a constant debt-equity ratio, debt finance must also increase at the same rate. Hence the policy $p=0$ may force the firm's total capital stock to grow at a rate that exceeds the rate of growth of the economy. In this event the risk class represented by this firm's securities would become very large relative to the market, and it would not be able to raise enough capital in the long run. Since we are restricting firms to choose steady policies only, such a program would be infeasible. The firm could sustain a rate of growth higher than the economy as a whole in the short run only, but the ensuing shifts in the $\phi$ and $\psi$ schedules would eventually cause the zero profit condition to be violated.

The rate of growth of the effective labor force is denoted by $n$. The firm operates under the constraint, $n \geqq(1-p) e$. Growing at a faster rate would cause the firm to become too large a risk relative to the remainder of the economy and would thus raise its cost of capital. The firm's problem is therefore

$$
\min N=b(1-\tau) i+(1-b) e
$$

subject to

$$
n \geqq(1-p) e .
$$

Writing the cost of capital as

$$
N=b(1-\tau) \phi /(1-\theta)+(1-b) \psi / x,
$$

we see that the Lagrangean for this problem is

$$
L=b(1-\tau) \frac{\phi}{1-\theta}+(1-b) \frac{\psi}{x}+\rho\left(n-(1-p) \frac{\psi}{x}\right)
$$

where $\rho$ is the Lagrange multiplier of the growth-rate constraint. Differentiating with respect to $b, p$, and $\rho$, we obtain the firm's optimality conditions:

$$
\begin{aligned}
& 0=\frac{1-\tau}{1-\theta}\left(i_{N}+b \phi^{\prime}\right)-\frac{e_{N}}{x}+\frac{(1-b)}{x} \psi^{\prime}-\rho \frac{(1-p) \psi^{\prime}}{x} \\
& 0=(1-b) e_{N}(\mu \theta-\theta) / x^{2}+\rho e_{N}(-x+(1-p) \theta(1-\mu)) / x^{2}
\end{aligned}
$$

6. We consider only steady policies-that is, choices of $p$ and $b$ that could be pursued indefinitely - throughout this paper. 


$$
0=n-(1-p) e_{N} / x,
$$

where $\phi^{\prime}$ and $\psi^{\prime}$ are the derivatives with respect to $b$. Solving (1.12) for $\rho$, we have

$$
\rho=-(1-b) \theta(1-\mu) /(1-\theta) .
$$

Note that $\rho$ is negative as might have been anticipated. A higher growth rate would make feasible a financial policy in which retentions increase sheltering equity income to a greater extent, thus lowering the gross return equivalent to the required net return. obtain

Substituting the solution for $\rho$ into (1.11) and simplifying, we

$$
0=\frac{1-\tau}{1-\theta}\left(i_{N}+b \phi^{\prime}\right)-\frac{e_{N}}{x}+\frac{(1-b) \psi^{\prime}}{1-\theta} .
$$

Equations (1.13) and (1.15) describe the first-order conditions for the firm's problem of selecting a debt proportion $b$ and a payout ratio $p$ that minimizes the cost of capital subject to the firm's equity growth constraint. ${ }^{?}$

\subsection{Aggregate Portfolio Balance Conditions}

The analysis above is a complete specification of the suppliers of corporate securities. To close the system, some description of investors' risk preferences and their resulting market behavior must be given. The simplest method is to write the market's desired, or acceptable, level of debt per unit of capital as

$$
\hat{b}=\eta\left(\hat{i}_{N}-\hat{e}_{N}\right)
$$

The sign of $\eta^{\prime}$ can be either positive or negative. We shall deal primarily with the case of $\eta^{\prime}=0$ to isolate risk changes from other effects, but we shall also discuss other cases.

Because of the symmetry of firms, in equilibrium the market (careted) variables will equal the corresponding firm-specific variables $\hat{b}=b, \hat{i}_{N}=i_{N}, \hat{e}_{N}=e_{N}$. This reduces the system to a determination of $b, i_{N}, e_{N}$, and $p$. Of course, in this determination each individual

7. For a given economic environment, as specified by $\hat{b}, \hat{e}_{N}, \hat{i}_{N}, n$, and the functions $\phi$ and $\psi$, the term's choice of $b$ and $p$ that minimizes the cost of capital may not also satisfy the equilibrium cash flow condition (1.5). If these choices were actually affected, there would be a surplus or deficit in the firm of $z=\left(f^{\prime}-b i\right)(1-\psi)-e(1-b)$, which it is natural to assume, would accrue to equity as they are the residual claimants. Thus, the true disequilibrium return to equity would be $z /(1-b)+e$. Investors would be off their $\psi$ schedules, and an adjustment would be necessary. In this paper we do not give any specification of the process of achieving equilibrium. It would be necessary to do so if one were to use the assumed stability of such a mechanism to derive comparative static results. 
firm treats the market variables $\left(\hat{b}, \hat{i}_{N}, \hat{e}_{N}\right)$ as given parameters of its own problem.

\subsection{The Complete System}

Using equations (1.3) and (1.8a) to write $p$ in terms of $x$ and the rate of growth, we see that in the long run, the system can be specified by the four relations,

$$
\begin{gathered}
0=b-\eta\left(i_{N}-e_{N}\right) \\
0=f^{\prime}-\frac{b i_{N}}{1-\theta}-\frac{1-b}{1-\tau} \frac{e_{N}}{x} \\
0=(1-\mu) \theta x n-(x+\theta-1) e_{N} \\
0=\frac{1-\tau}{1-\theta}\left(i_{N}+b \phi^{\prime}\right)-\frac{e_{N}}{x}+\frac{(1-b) \psi^{\prime}}{1-\theta},
\end{gathered}
$$

which are, respectively, the portfolio balance condition, the financial balance condition, and the two first-order conditions for the firm's optimization.

\section{Notation}

For the reader's convenience, before proceeding, our notation is recapitulated below in tabular form:

Tax Rates

$\theta=$ personal income tax rate, applicable to interest and dividend income.

$\mu \theta=$ personal tax rate on retained earnings (through eventual capital gains).

$\tau=$ corporate tax rate on profits; interest is deductible.

Financial Variables for the Firm

$e=$ cost of equity finance.

$i=$ cost of debt finance.

$b=$ debt as a proportion of capital.

$p=$ payout rate, the proportion of post-corporate tax earnings paid in the form of dividends.

$e_{N}=$ the supply price for net rate of return on equity of the firm.

$i_{N}=$ the supply price for net rate of return on debt of the firm. 
Macroeconomic Variables

$f^{\prime}=$ gross return per unit of capital.

$n=$ rate of growth.

$\hat{b}=$ market debt as a proportion of capital stock.

$\hat{e}_{N}=$ market rate of return on equity.

$\hat{i}_{N}=$ market rate of return on debt.

\section{Effects of Changes in the Profit Tax Rate}

In this section we examine how an increase in the rate of profits tax affects the decisions of the representative firm and the net returns to debt and equity investors. The differential taxation of dividends and retained earnings (i.e., the value of $\mu$ ) is assumed to remain unchanged. ${ }^{8}$

Our analysis will focus primarily on the case in which $\eta^{\prime}=0$; i.e., in which the debt-to-capital ratio (b) remains fixed because the market's demand for relative quantities of debt and equity is not sensitive to differences in their yields. We focus on this case because only when $b$ is constant can the predicted changes in $e_{N}$ and $i_{N}$ be interpreted unambiguously. With a fixed debt-capital ratio, the values of $e_{N}$ and $i_{N}$ are good reflections of the welfare of the owners of debt and equity capital. In contrast, when $b$ changes in response to a change in the tax law, parts of the observed changes in $e_{N}$ and $i_{N}$ reflect compensation for the new level of risk associated with the new value of $b .{ }^{9}$

Totally differentiating equations (1.17)-(1.20) in the general case of $\eta^{\prime} \neq 0$ with respect to $b, e_{N}, i_{N}, x$, and the predetermined $\tau$ yields ${ }^{10}$

$$
\left[\begin{array}{cccc}
1 & \eta^{\prime} & -\eta^{\prime} & 0 \\
\frac{1-\tau}{1-\theta} i_{N}-\frac{e_{N}}{x} & \frac{1-b}{x} & \frac{1-\tau}{1-\theta} b & -\frac{(1-b) e_{N}}{x^{2}} \\
0 & 1-x-\theta & 0 & (1-\mu) \theta n-e_{N} \\
Z & -\frac{1}{x} & \frac{1-\tau}{1-\theta} & \frac{e_{N}}{x^{2}}
\end{array}\right]\left[\begin{array}{l}
d b \\
d e_{N} \\
d i_{N} \\
d x
\end{array}\right]
$$

8. Section III considers changes in $\mu$ as well as compensated increases in $\tau$ and decreases in $\mu$ that keep total tax revenue unchanged. In contrast, the increase in $\tau$ in the current section increases tax revenues.

9. A more complete analysis of risk and risk aversion would be required to provide a precise welfare measure.

10. Recall that we have assumed that the cross-derivatives of $\phi$ and $\psi$ are zero. 


$$
=\left[\begin{array}{c}
0 \\
\frac{b i_{N}}{1-\theta}-f^{\prime} \\
0 \\
\frac{i_{N}+b \phi^{\prime}}{1-\theta}
\end{array}\right] d \tau,
$$

where $Z=\partial^{2} N / \partial b^{2}$. The second-order condition for choosing $b$ to minimize the cost of capital implies that $Z>0$.

\subsection{The Debt-Capital Ratio}

Although we shall concentrate on the case in which inelastic market demand $\left(\eta^{\prime}=0\right)$ keeps the debt-capital ratio $(b)$ fixed, it is useful to examine first the effect of the corporation tax on the debt ratio in the more general case in which $\eta^{\prime} \neq 0$. Solving (2.1) implies that

$$
\begin{aligned}
\frac{d b}{d \tau}= & \Delta^{-1} \eta^{\prime}\left\{\frac{e_{N}}{x}\left(\frac{i_{N}}{1-\theta}-\tau f^{\prime}\right)\right. \\
& -b \phi^{\prime}\left[\frac{1-\tau}{1-\theta} b\left((1-\mu) \theta n-e_{N}\right)+\frac{1-b}{x}\left((1-\mu) \theta n-e_{N}\right)\right. \\
& \left.\left.+\frac{(1-b) e_{N}}{x^{2}}(1-x-\theta)\right]\right\}
\end{aligned}
$$

where $\Delta$, the determinant of the matrix in (2.1), is

$$
\Delta=\frac{1-\tau}{1-\theta} \frac{e_{N}}{x}+\eta^{\prime} Z-\eta^{\prime} \tau\left[\frac{1-\tau}{1-\theta} b \phi^{\prime}+\frac{1-b}{1-\theta} \psi^{\prime}+Z b\right] .
$$

Consider first the case in which $\eta^{\prime}>0$. Equations (2.2) and (2.3) show unambiguously that the introduction of a corporate income tax induces a substitution of debt for equity finance when $\tau=0$. Equations (2.2) and (2.3) then yield

$$
\begin{aligned}
\frac{d b}{d \tau}= & \eta^{\prime}\left\{i_{N} e_{N}-b \phi^{\prime}\left[\left(\frac{b}{1-\theta}+\frac{1-b}{x}\right)\left((1-\mu) \theta n-e_{N}\right)\right.\right. \\
& \left.\left.+\frac{(1-b) e_{N}}{x^{2}}(1-x-\theta)\right]\right\}>0,
\end{aligned}
$$

since $(1-\mu) \theta n=\left((\theta-1) e_{N}\right) / x<0$ and $(1-x-\theta)=-(1-p)(1-$ $\mu) \theta<0$. It is easy to understand the reason for this. The corporation tax permits the deduction of interest payments in the calculation of taxable income. It thus raises the cost to the firm of providing a dollar 
of net equity income relative to the cost of providing net interest income. The firm's cost of capital is therefore minimized by substituting debt for equity. The extent of this substitution is limited by the market's reaction to the increased riskiness implied by an increasing ratio of debt to equity.

If $\eta^{\prime}<0$, the numerator is negative, and $d b / d \tau>0$ only if the denominator is also negative. The sign of the denominator can be negative if $\eta^{\prime}<0$, but without quantitative information on the magnitudes of $\eta^{\prime}$ and $Z$, it is not possible to be certain of the sign. Stability considerations do not provide a definite answer unless arbitrary restrictions are imposed on the adjustment process.

\subsection{The Net Rate of Interest}

Previous studies of the corporation tax have not provided a satisfactory analysis of the effect of the tax on the net rate of interest received by bondholders. Harberger's [1962] discussion of corporate tax incidence ignored debt completely and assumed that all investment is equity financed. Stiglitz [1973] considered the opposite extreme case in which all marginal investment is financed by debt and therefore in which a change in the corporate tax rate does not alter the net rate of interest; i.e., $d i_{N} / d \tau=0$.

We now show that when firms combine debt and equity financé, the introduction of a corporation tax (or the increase in a pre-existing tax rate) with full interest deductibility reduces the net yield to bondholders. To abstract from changes in $i_{N}$ that just compensate for the increased debt-equity ratio, we consider the case in which $\eta^{\prime}$ $=0$ and therefore $b$ is constant. Equations (2.1) and (2.3) then imply that

$$
\frac{d i_{N}}{d \tau}=\frac{-(1-\theta)}{1-\tau}\left\{f^{\prime}-i-b \phi^{\prime}(1-b)\left(x-1+\theta+\frac{1-\theta}{x}\right)\right\} .
$$

Using (1.18) and (1.20), we see that a lower bound on the bracketed expression in (2.5) can be obtained under the condition $\psi^{\prime}=0$, as

$$
(1-b) b \phi^{\prime}\left(\frac{1}{1-\theta}-x+1-\theta-\frac{(1-\theta)}{x}\right) \text {. }
$$

This expression can be seen to be positive. Therefore, $d i_{N} / d \tau$ is always negative. (Typically, $\psi^{\prime}$ will be positive even when $\phi^{\prime}$ is very small because equity risk is more sensitive to corporate leverage than is the default risk on debt.)

It may at first seem paradoxical that a higher rate of corporation tax changes the yield on debt even though interest payments are fully 
deductible in calculating the corporation's taxable income. Looked at in this way, it would seem that the interest rate should be unaffected by a corporation tax and that all of the tax should be absorbed by a reduction in equity income. ${ }^{11}$ Such an outcome is not compatible with the firms' financing and cost minimization conditions (equations (1.18), (1.19), and (1.20)). If the interest rate remained unchanged, firms would try to reduce their supply of bonds; since $\eta^{\prime}=0$ implies that $b$ cannot change, equilibrium must be re-established by a fall in $i_{N}$.

To obtain an indication of the order of magnitude of the effect of changes in the corporate tax rate, we can evaluate equation (2.5) for plausible values of the relevant parameters under the further assumption that $\phi^{\prime}=0 .{ }^{12} \mathrm{We}$ shall set the effective rate of corporate income tax at $\tau=0.40$ and the personal tax rate on bond interest and dividend income at $\theta=0.30$, values that are roughly appropriate for the United States. The marginal product of capital of U. S. nonfinancial corporations has been about $f^{\prime}=0.11$ in the past twenty-five years [Feldstein and Summers, 1977]. The real rate of interest on medium grade corporate bonds has been approximately $i=0.03 .{ }^{13}$ Substituting these figures into (2.5) implies that $d i_{N} / d \tau=-0.093$. An increase in the effective corporate tax rate by 0.1 (i.e., from 0.40 to 0.50 ) would lower $i_{N}$ by 0.93 percentage points. Since $i=0.03$ and $\theta=0.3 \mathrm{imply} i_{N}=0.021$, this would cut the net yield nearly in half. Note also that a fall of 0.93 in $i_{N}$ implies a fall of $0.93 /(1-\theta)=1.3$ percentage points in the real rate of interest, from 3.0 to 1.7 percent. ${ }^{14}$

\subsection{The Net Yield on Equity}

The fall in the net rate of interest that we have just calculated shows that the burden of the corporation tax is borne by both debt and equity investors. To assess the share borne by each, we must complement the calculation of the previous section by calculating the effect on $e_{N}$ of an increase in the corporate tax rate.

11. Recall that we are dealing with the case of $\eta^{\prime}=0$ in which individual investors wish to hold the same portfolio regardless of the relative values of $i_{N}$ and $e_{N}$. With $\eta^{\prime}$ $>0$, a fall in $e_{N}$ would increase the households demand for bonds and this in turn would be a further reason for $i_{N}$ to fall.

12. The magnitude of $\phi$ cannot be ascertained in general, since it depends on the substitutability among debt issues in investors' portfolios. Close substitutability implies that $\phi$ is small.

13. During a decade of relative price stability (1954-1964), the yield on Moody's Baa bonds averaged 4.6 percent and the implicit price deflator for gross domestic product rose at 2.0 percent a year.

14. The issue is more complex where there is a positive rate of inflation. See Feldstein, Green, and Sheshinski [1978]. 
It follows directly from equations (2.1) and (2.3), that, with $\eta^{\prime}=$ 0 ,

$$
\frac{d e_{N}}{d \tau}=\frac{\left[(1-\mu) \theta n-e_{N}\right]\left(f^{\prime}+\left(b^{2} \phi / 1-\theta\right)\right)}{e_{N} / x} .
$$

Since equation (1.19) implies that $(1-\mu) \theta n-e_{N}=(\theta-1) e_{N} / x$, we have that when $\phi^{\prime}=0,(2.6)$ simplifies to

$$
\frac{d e_{N}}{d \tau}=-(1-\theta) f^{\prime}
$$

This is a striking result. It implies that the reduction in the equilibrium equity yield in response to an increase in the corporate tax rate is independent of the debt-equity ratio, the dividend payout rate, and the preferential treatment of retained earnings ${ }^{15}$ when corporations' borrowing rates are perfectly elastic.

The numerical values suggested above imply that $d e_{N} / d \tau=$ -0.077 . An increase in the corporate tax rate from 0.40 to 0.50 would thus lower $e_{N}$ by 0.77 percentage points, less than the reduction in the net interest rate.

Total income of equity investors per dollar of capital is $E_{N}=$ $(1-b) e_{N}$ and the corresponding income of bondholders is $I_{N}=b i_{N}$. The relative income changes can therefore by written directly from equation $(2.1)$ as

$$
\begin{aligned}
\frac{d E_{N} / d \tau}{d I_{N} / d \tau} & =\frac{1-b}{b} \frac{d e_{N} / d \tau}{d i_{N} / d \tau} \\
& =\frac{1-b}{b} \cdot \frac{(\theta-1)\left(e_{N} / x\right)(1-\tau) /(1-\theta) f^{\prime}}{\left(-e_{N} / x\right)\left(f^{\prime}-i_{N} /(1-\theta)\right)} \\
& =\left(\frac{1-b}{b}\right)(1-\tau)\left[\frac{f^{\prime}}{f^{\prime}-i}\right]
\end{aligned}
$$

With our values of $\tau=0.40, f^{\prime}=0.11$, and $i=0.03$, and $b=0.03$, $d E_{N} / d \tau=1.925\left(d I_{N} / d \tau\right)$. Equity owners bear only about 66 percent of the tax, even though they account for 92 percent of the pretax corporate income and 89 percent of the after-tax income. ${ }^{16}$

15. Note that equations (2.5) and (2.7) together imply that introducing a new corporate income tax reduces the earnings on the average portfolio of debt and equity by $d\left[b_{i N}+(1-b) e_{N}\right] d \tau=-(1-\theta)\left(f^{\prime}-b i\right)$. This is of course just the revenue raised by taxing the return to equity, $f^{\prime}-b i$, when the net income is otherwise subject to personal tax at rate $\theta$.

16. On a pretax basis, bondholders receive only $b i=0.009$ per dollar of capital while equity receives (before tax) $(1-b) e=f^{\prime}-b i=0.101$ per dollar of capital. Net of tax, bondholders receive $(1-\theta) b i=0.0063$ per dollar of capital. To calculate the net income of equity investors, $(1-b) e_{N}=x(1-b) e$, note that $x=p(1-\theta)+(1-$ $p)(1-\mu \theta)$. Values of $p=0.5$ for the dividend payout ratio and $\mu=0.2$ for the relative 


\subsection{The Dividend Payout Ratio}

We turn finally to the effect of the corporation tax on the dividend payout ratio $p$. Recall that the balanced growth of the corporation at the common growth rate of the economy $(n)$ requires that the corporation's equity also grow at this rate. Equation (1.8a) noted that this balanced growth condition could be written as

$$
n=(1-p) e .
$$

If we substitute $e_{N}$ for $e$, this becomes

$$
n=\frac{1-p}{p(1-\theta)+(1-p)(1-\mu \theta)} e_{N}
$$

When an increase in the corporate tax rate lowers $e_{N}$, the balanced growth condition requires an offsetting increase in the remaining part of the right-hand side of (2.10). Since this expression varies inversely with $p$ for any feasible values of $\theta$ and $\mu$, an increase in the corporate tax rate requires a reduction in the dividend payout rate. ${ }^{17}$

We calculated that, with $b$ constant, increasing from 0.40 to 0.50 would reduce $e_{N}$ by 0.0077 . Since $e_{N}=0.071$ at the initial numeral values, ${ }^{18}$ this is a reduction of 10.8 percent. To continue to satisfy the balanced growth equation, the dividend payout ratio must fall from 0.50 to $0.43 .{ }^{19}$

\section{EFFects of Changes In the TAXATION OF RETAINED EARNINGS}

A central feature of the corporate-type tax is that retained earnings are taxed at a lower effective rate than dividends. Under current U.S. law, retained earnings are not subject to any personal income tax as such. The resulting capital gains are taxed at a rate less than the rate on dividend income, and the tax is assessed only when the asset is sold. We have parameterized the extent to which retained earnings are sheltered by $\mu: \mu=1$ representing no advantage to retained earnings over dividend income, and $\mu=0$ representing a zero

rate of tax on retained earnings (allowing for the effect of postponement and the lower capital gains tax rate) are reasonable for the United States; these imply that $x=0.82$. From $(1-b) e=(1-\tau)\left(f^{\prime}-b i\right)$, we obtain $(1-b) e_{N}=x(1-\tau)\left(f^{\prime}-b i\right)=0.497$. Total after-tax income per dollar of capital is therefore 0.0560 of which equity investors receive 89 percent.

17. More formally, it can be shown that $1 /(1-p) d(1-p) / d \tau=-f^{\prime} / e$.

18. Note 16 showed that $(1-b) e_{N}=0.497$. Since $b=0.3, e_{N}=0.071$.

19. More generally, equation (2.1) can be used to calculate $d x / d \tau$ and then $d p / d \tau$ derived by using the definition that $x=(1-\mu \theta)-(1-\mu) \theta p$. 
effective tax on retained earnings. Thus, differentiating with respect to $\mu$ corresponds to studying decreased levels of sheltering.

The effects of changing $\mu$ run through two channels. Directly, $\mu$ alters the effective tax rate on equity income $x$. Thus, $\mu$ influences the cost of capital for fixed values of $e_{N}$ and $i_{N}$. Indirectly, the induced change in $e$, after firms have adjusted to the new cost of capital, will influence the payout rate $p$ necessary to satisfy the steady-state equation. This feeds back onto the effective tax rate because it alters the part of equity income that is sheltered.

Intuitively, we would expect to find that reducing the extent of sheltering lowers the after-tax total return to equity $e_{N}$. This is true in this model. Moreover, we shall show that changes in the retained earnings provisions are otherwise neutral (provided that $\eta^{\prime}=0$ ), leaving the gross returns, the net interest rate, and the dividend payout rate unaffected.

\subsection{Uncompensated Shifts in $\mu$}

Recall that our basic equation system, (1.17)-(1.20), and its total differentiation (2.1) are written in terms of the endogenous variables, $b, e_{N}, i_{N}$, and $x$, with $\mu$ as a fixed parameter. This form is inconvenient for the purpose of studying the effects of varying $\mu$ because $\mu$ enters into the definition of $x$. By rewriting the system with $p$, instead of $x$, as the fourth endogenous variable, we can see the effects of $\mu$ more simply. To do so, note that $p, \mu$, and $x$ are related by the definition,

$$
x \equiv p(1-\theta)+(1-p)(1-\mu \theta) .
$$

Thus, in differentiating (1.20)-(1.23) totally with respect to $b, e_{N}, i_{N}$, $p$, and $\mu$, it is only necessary to use

$$
\frac{\partial x}{\partial \mu}=-\theta(1-p)
$$

$$
\frac{\partial x}{\partial p}=-\theta(1-\mu)
$$

to convert (2.1) into an equivalent system in these variables. This gives 
$\left[\begin{array}{cccc}1 & \eta^{\prime} & -\eta^{\prime} & 0 \\ \frac{1-\tau}{1-\theta} i_{N}-\frac{e_{N}}{x} \frac{1-b}{x} \frac{1-\tau}{1-\theta} b & \frac{(1-b) e_{N} \theta(1-\mu)}{x^{2}} \\ 0 & 1-\theta-x & 0 & -\left[(1-\mu) \theta n-e_{N}\right] \theta(1-\mu) \\ Z & \frac{-1}{x} & \frac{1-\tau}{1-\theta} & \frac{-e_{N}}{x^{2}} \theta(1-\mu)\end{array}\right]\left[\begin{array}{l}d b \\ d e_{N} \\ d i_{N} \\ d p\end{array}\right]$
$=\left[\begin{array}{c}-(1-b) \frac{e_{N} \theta(1-p)}{x^{2}} \\ {\left[(1-\mu) \theta n-e_{N}\right] \theta(1-p)+\theta n x} \\ \frac{e_{N} \theta(1-p)}{x^{2}}\end{array}\right] d \mu$.

The matrix on the left-hand side of (3.3) is just the same as that in (2.1) with the last column multiplied by $d x / d p=-\theta(1-\mu)$. Thus assuming that $\eta^{\prime}=0,{ }^{20}$ we see that its determinant is

$$
-\Delta \theta(1-\mu)=-\frac{1-\tau}{1-\theta} \frac{e_{N} \theta(1-\mu)}{x} .
$$

We obtain the following comparative static results:

$$
\begin{gathered}
\frac{d e_{N}}{d \mu}=-\theta n<0 \\
\frac{d i_{N}}{d \mu}=0 .
\end{gathered}
$$

The particularly simple form of these expressions is worthy of note. The decrease in $e_{N}$ in response to a higher effective tax on equity is no surprise. Its dependence on $n$, the growth rate, results from the fact that retentions are constrained in equilibrium by the growth rate. Therefore, in a faster growing economy with a higher retention rate, the nature of the taxation of retained earnings and capital gains will be more important to equity owners.

The result that $i_{N}$ is unaffected is somewhat more surprising and

20. Throughout this section we shall maintain this condition. Little in the way of precise analytic results can be obtained if the aggregate debt-equity ratio is flexible and can respond to shifts in the composition of the cost of capital. Of course, on the firm level in our model, the cost of capital can be affected by financing changes of this type. 
is an important conclusion that follows from the behavioral equations of the model. When $\mu$ increases, the initial impact is felt on all the equations of the system (except $b=\eta\left(i_{N}-e_{N}\right)$, which does not matter when $\eta^{\prime}=0$ ). The firm has a cash flow deficit, as can be seen from equations (1.18) and (3.2). The retention ratio is no longer compatible with a steady state (from (1.19)); and bond finance becomes underutilized, since the value of $e$ necessary to provide the original net return $e_{N}$ is higher. It is important to note that if $e_{N}$ and $p$ were to change so as to restore cash-flow balance, they would also re-equilibrate the cost of capital at its original level. This can be seen simply by noting that $e_{N}$ and $p$ enter both of these equations in the form $e_{N} / x$ only. Since $i_{N}$ does not enter the steady-state equation at all, it is clear that the new equilibrium is achieved only by changing $e_{N}$ and $x$, and leaving $i_{N}$ at its original level. ${ }^{21}$

To summarize in economic terms, the constancy of $i_{N}$ results from the fact that the cost-of-capital equation and the cash flow equation both embody $e_{N}, x$, and $\mu$ in precisely the same functional form. Viewed in this way the result is no surprise at all. These equilibrium relations are concerned with firms' behavior and as such depend only on the returns to capital gross of personal taxation; in particular, the tax on retained earnings enters only through $e$, which is fixed in steady-state equilibrium.

Note that since $i_{N}$ and $\theta$ are unchanged, so is $i$. Therefore, the cost of capital minimization can be compatible with a fixed $b$ only if $e$ is also unchanged.

From the steady-state condition, $n=(1-p) e$, it is clear that $p$ must also be constant. An uncompensated for change in the sheltering provision for retained earnings affects only the net return to equity through a shift in the effective tax on equity income. There are no further repercussions through the general equilibrium of the system. In this sense the differential taxation of retained earnings, unlike the corporate profits tax itself, is neutral. ${ }^{22}$

\subsection{Compensated Shifts in $\mu$}

In concluding this section, it is interesting to ask what happens when $\mu$ and $\tau$ are changed simultaneously in a way that keeps the net burden of the tax unchanged while increasing the degree of sheltering of retained earnings. In our notation this involves lowering $\mu$ and

21. This follows formally from the singularity of the matrix in (3.3), when the coefficients of $d \mu$ are substituted for the third column.

22 . It should be emphasized again that this neutrality holds only in the special case of $\eta^{\prime}=0$ that we are examining in this section. 
raising $\tau$ in a way that keeps $b i_{N}+(1-b) e_{N}$ unchanged. ${ }^{23}$ This can also be interpreted as making the tax more like a corporation tax. In the extreme case of complete integration of the personal and corporate taxes, $\mu=1$, and $\tau=0$; there is then no difference in the taxation of dividends, retained earnings, and interest; as $\mu$ falls and $\tau$ rises, we move toward the current type of corporation tax.

Since an increase in $\tau$ lowers $i_{N}$, while a change in $\mu$ does not alter $i_{N}$, the combined change in $\tau$ and $\mu$ also lowers $i_{N}$. The requirement that the net portfolio yield $\left(b i_{N}+(1-b) e_{N}\right)$ remain unchanged implies that $e_{N}$ must rise. As the equal yield tax changes in the direction of a corporate-style tax, the net equity yield increases, while the net return on debt falls. Moreover, since $d p / d \tau<0$ and $d p / d \mu=$ 0 , the compensated change of increased sheltering has the effect of increasing the fraction of income that is retained.

\section{The Nonneutrality of THE CORPoRATE Income TAX}

Our analysis has shown that the current structure of corporate and personal taxes can substantially distort the financial behavior of firms. This occurs, even though we have assumed that the stock of capital at each instant of time is fixed and that all business activity occurs in a corporate form. If we drop either of these assumptions, there is a further source of distortion in either the intertemporal or intersectoral allocation of resources. Before discussing the possibility of such additional distortions, we shall examine the nature of the nonneutrality of the corporation tax in a one-sector economy with a fixed growth rate.

Consider first the nonneutrality of the tax law with respect to the debt-equity ratio. Our analysis showed that the current tax system induces firms to increase their debt-equity ratio. The essential reason for this substitution is that interest payments are deductible in calculating taxable income, while the returns to equity are not. The extent of the substitution is limited because every rise in the firm's debt-equity ratio increases the perceived uncertainty of the firm's interest and equity payments, and this perceived risk raises the cost to the firm of both debt and equity capital. A new equilibrium debtequity ratio is established at the point where the tax advantage of deductibility just balances the cost induced by the increased riskiness of heavier leverage.

This analysis stands in sharp contrast to two models recently

23. Recall that we are assuming that $\eta^{\prime}=0$ and therefore that $b$ is fixed. Fixing the net portfolio yield $b i_{N}+(1-b) e_{N}$ is equivalent to fixing the net burden of the tax. 
developed by Stiglitz that imply that the corporation tax does not affect the debt-equity ratio. In the first model Stiglitz [1973] postulated that firms retain all of their earnings (i.e., pay no dividends) and can borrow at a fixed interest rate to finance investment in excess of these retained earnings. Since all marginal investments are financed wholly by debt in that model, the introduction of a corporate income tax has no effect. The important contribution of that paper is the reminder that previous studies of the corporation tax have been deficient in assuming that all corporate investment is financed wholly by equity. Stiglitz's own assumption that firms can borrow as much as they want at a fixed interest rate is crucial to his conclusion. Stiglitz explicitly recognizes that his assumption would only be tenable in an economy in which there is no uncertainty and would then imply that the marginal product of capital equals the rate of interest $\left(f^{\prime}=i\right)$. The inability of this model to explain why any dividends are paid is a further warning against accepting its other conclusions. ${ }^{24}$

In a subsequent analysis Stiglitz [1976, Section 5] developed a quite different model in which the interest rate paid by the firm is an increasing function of the firm's debt-equity ratio. In the context of this model Stiglitz again concluded that a corporate income tax would not change the firm's optimal debt-equity ratio. More specifically, Stiglitz posited an individual investor who divides his wealth between investment in a corporation (which he controls and which also borrows from others at a rate of interest that is an increasing function of the firm's debt-equity ratio) and investment in an unspecified alternative asset with a fixed return. In Stiglitz's formulation of the problem, the introduction of a corporate income tax does not alter the investor's optimal investment or borrowing decisions. This conclusion rests on the unwarranted assumption that the introduction of a corporation tax at rate $\tau$ reduces the net yield on the "alternative asset" by the same factor of $1-\tau$ that is applied to net corporate income. ${ }^{25}$ No reason is offered for this critical assumption. Moreover, the assumption is clearly false if the "alternative asset" is assumed to be the market portfolio of debt and equity or the debt issued by other corporations. The yield on the alternative asset will fall by the corporate tax rate only if this alternative asset consists exclusively of equity in other firms. However, this implies that any individual who owns corporate equity invests only in corporate equity regardless of the tax,

24. These remarks should not be regarded as a criticism of Stiglitz's model (which we believe makes an important analytic contribution) but as an explanation of why its implications should not be regarded as directly relevant for any actual economy.

25 . The crucial character of this assumption is clear, since Stiglitz's argument rests on the tax simply multiplying all terms in the first-order condition by $1-\tau$. 
while corporate bonds are held by a wholly separate group. It thus appears that Stiglitz's result that the debt-equity ratio remains unaffected by the tax follows from an implicit assumption that there are two classes of investors, one of which invests only in equity while the other invests only in debt. We therefore reject the "neutrality" conclusion of Stiglitz's second model.

In their justifiably famous article Modigliani and Miller [1958] showed that under certain conditions a firm's debt-equity ratio is indeterminate. One of these crucial conditions is the absence of any taxes. The introduction of the corporation tax in the simplest Modigliani-Miller framework implies that firms will finance their investment by debt only. In his recent Presidential address to the American Finance Association, Miller [1976] surveys the attempts to extend the model to include taxes without reaching this extreme and unrealistic implication. Miller concluded correctly that previous analyses have ignored the tax features that favor equity finance, i.e., the absence of any personal tax on retained earnings and the relatively low rate of tax on capital gains. He then argues that this favorable treatment of equity could re-establish the indeterminacy of the debt-equity ratio and could therefore explain (without introducing considerations of risk related to the debt-equity ratio) why firms have not relied more on debt finance. More specifically, Miller points out that the debtequity ratio is indeterminate if (in our notation) $(1-\theta)=(1-\tau)$ $\times[p(1-\theta)+(1-p)(1-\mu \theta)]$; i.e., if the after-tax yields on debt and equity are equal. However, since $\theta<\tau$ and $p(1-\theta)+(1-p)(1-\mu \theta)$ $<1$, this required "indifference condition" is definitely not satisfied in practice. Although Miller is right to stress the full structure of tax incentives, we believe the observed mix of debt and equity can be explained only by incorporating the risk-premium effects of changes in the debt-equity ratio (i.e., $\phi^{\prime}>0$ and $\psi^{\prime}>0$ ). ${ }^{26}$

In addition to noting the potential effect of the corporation tax on the debt-equity ratio, our own analysis pointed out that the corporate tax lowers the net rate of interest ${ }^{27}$ (as well as the yield on equity capital) and reduces the dividend payout rate. Thus, even in the case of an all-corporate economy with a fixed capital stock, the corporate income tax affects every margin of choice.

26. Miller appears to accept this at certain places in his address but generally stresses the "indifference condition" and minimizes the importance of uncertainty. Since Miller does not present an explicit complete model, we are uncertain of his final judgment.

27. Stiglitz [1973] concluded that the net rate of interest would be unchanged by the corporation tax, but this rests on the assumption that marginal investments are financed wholly by debt and thus indirectly on the assumption of a riskless economy. 
It is useful to consider the implications of extending our analysis to the type of two-sector economy studied by Harberger $[1962,1966]$. In this economy, fixed total supplies of capital and labor are divided between corporate and noncorporate production. All capital is equity capital. The introduction of a tax on capital income in the corporate sector involves an excess burden because the allocation of capital and labor between the two sectors is distorted. The introduction of debt finance along the lines developed in our model does not eliminate this excess burden. It is clear from Section II that $i_{N}$ and $e_{N}$ are both decreased by the introduction of a corporate income tax; this would induce a shift of capital from the corporate to the noncorporate sector until the net rates of return were again in equilibrium. ${ }^{28}$ Note that this change in the allocation of capital and labor might also change the marginal product of labor.

If the savings rate is not fixed, but depends on the net yield to savers, the corporate income tax will also distort the intertemporal allocation of resources. In the all-corporate economy, the corporate tax reduces $i_{N}$ and $e_{N}$ and therefore the return on the market portfolio. This raises the price of future consumption relative to the price of current consumption and therefore distorts individual consumption and saving decisions. This entails an efficiency loss even if there is no net change in private saving [Feldstein, 1977]. The distortion is more complex in an economy with noncorporate as well as corporate firms but the conclusion concerning a potentially large intertemporal misallocation of resources remains unchanged.

\section{CONCLUSION}

In this paper we have examined the long-run effects of a corporate-type profits tax in a growing economy. Our model explicitly includes optimization by individual firms of their debt-equity ratio and dividend payout rate.

The analysis shows that the corporate-style tax is nonneutral in several important ways even though debt finance is available and the interest payments are deductible in the calculation of taxable income. Even if the economy's saving rate is fixed and all business activity occurs in the corporate form, changes in the tax rate would alter the firms' debt-equity ratio and the dividend payout rate as well as the net-of-tax rates of return earned on both equity and debt investments.

28. The corporation tax reduces the risk as well as the yield of corporate sector investment. The risk effect could in principle outweigh the yield effect and cause capital to flow into the corporate sector [Penner, 1964]. The implication would still be that the tax is distortionary and creates an excess burden. 
With a more general specification of saving behavior and the recognition of an untaxed noncorporate sector, it is clear that this reduction in the net equity and debt yields will alter both saving and the allocation of capital between the corporate and noncorporate sectors.

There are several directions in which the current model should be extended. We have ignored inflation here even though we previously found (with a simpler model) that the interaction of inflation and taxation can be of substantial importance. ${ }^{29}$ Although we have discussed the general implications of our research for a two-sector economy, an explicit analysis of the effect of a corporation tax when there is debt and equity finance of the type we analyze and an untaxed noncorporate sector remains to be done. Finally, we have dealt exclusively with the long-run, steady-state characteristics of the economy; it would clearly be useful to analyze the transitional behavior of both corporate borrowing and divi.:end decisions.

HaRVARd UNiVERSity and National BURliau of ECONOMIC RESEARCH HARVARD UNIVERSITY AND NATIONAL BURE HEBREW UNIVERSITY OF JERUSALEM

\section{REFERENCES}

Auerbach, A. J., "Wealth Maximization and the Cost of Capital," this Journal, XCIII (Aug. 1979), 433-46.

Bradford, D., "The Incidence and Allocation Effects of a Tax on Corporate Distributions," mimeographed, 1978.

Feldstein, Martin S., "Inflation, Income Taxes, and the Rate of Interest: A Theoretical Analysis," American Economic Review, LXVI, No. 5 (Dec. 1976), 809-20.

__. "The Welfare Cost of Capital Income Taxation," Journal of Political Economy, LXXXVI, No. 2, Part II (1978), S29-S51.

- , Jerry Green, and Eytan Sheshinski, "Inflation and Taxes in a Growing Economy with Debt and Equity Finance," Journal of Political Economy, LXXXVI, No. 2, Part 2 (1978).

_- , and Lawrence Summers, "Is the Rate of Profit Falling?" Brookings Papers on Economic Activity, 1 (1977).

Harberger, Arnold C., "The Incidence of the Corporate Income Tax," Journal of Political Economy, LXX (June 1962), 215-40.

_- "Efficiency Effects of Taxes on Income from Capital," in M. Krzyzaniak, ed., Effects of the Corporation Income Tax (Detroit: Wayne State University Press, 1966).

Jakobsson, Ulf, "Corporate and Personal Taxation and the Growing Firm," mimeo, 1974.

Lintner, John, "Optimal Dividends and Corporate Growth under Uncertainty," this Journal, LXXVIII, No. 1 (Feb. 1964), 49-95.

Miller, Merton H., "Debt and Taxes," Presidential Address delivered at the Annual Meeting of the American Finance Association, September 1976.

Modigliani, Franco, and Merton H. Miller, "The Cost of Capital, Corporation Finance and the Theory of Investment," American Economic Review, XLVIII (June 1958), 261-97.

29. See Feldstein [1976] and Feldstein, Green, and Sheshinski [1978]. 
Myers, Stewart C., "Determinants of Corporate Borrowing," Journal of Financial Economics, V (1977), 147-75.

Penner, R. G., "A Note on Portfolio Selection and Taxation," Review of Economic Studies, XXXI (Jan. 1964), 83-86.

Solow, Robert, "Some Implications of Alternative Criteria for the Firm," Ch. 10 in The Corporate Economy, R. Marris and A. Wood, eds. (New York: Macmillan, 1971), pp. 318-42.

Stiglitz, Joseph, "Taxation, Corporate Financial Policy, and the Cost of Capital," Journal of Public Economics, II, No. 1 (Feb. 1973), 1-34.

_- "The Corporation Tax," Journal of Public Economics, V, Nos. 3, 4 (April-May 1976), 303-11.

Tobin, J., "A General Equilibrium Approach to Monetary Theory," Journal of Money, Credit and Banking (Feb. 1969), 15-29. 
Copyright of Quarterly Journal of Economics is the property of MIT Press and its content may not be copied or emailed to multiple sites or posted to a listserv without the copyright holder's express written permission. However, users may print, download, or email articles for individual use. 